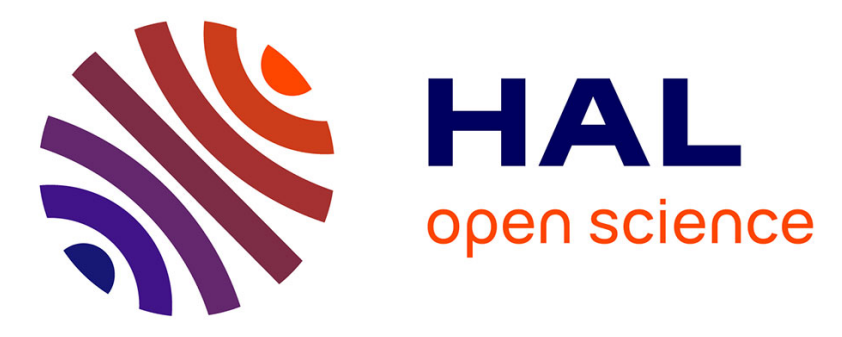

\title{
Site-Selective Synthesis of Janus-type Metal-Organic Framework Composites.
}

\author{
Sudarat Yadnum, Jérome Roche, Eric Lebraud, Philippe Négrier, Patrick \\ Garrigue, Darren Bradshaw, Chompunuch Warakulwit, Jumras Limtrakul, \\ Alexander Kuhn
}

\section{To cite this version:}

Sudarat Yadnum, Jérome Roche, Eric Lebraud, Philippe Négrier, Patrick Garrigue, et al.. SiteSelective Synthesis of Janus-type Metal-Organic Framework Composites.. Angewandte Chemie International Edition, 2014, 53 (15), pp.4001-4005. 10.1002/anie.201400581 . hal-00977090

\section{HAL Id: hal-00977090 https://hal.science/hal-00977090}

Submitted on 8 Jan 2018

HAL is a multi-disciplinary open access archive for the deposit and dissemination of scientific research documents, whether they are published or not. The documents may come from teaching and research institutions in France or abroad, or from public or private research centers.
L'archive ouverte pluridisciplinaire HAL, est destinée au dépôt et à la diffusion de documents scientifiques de niveau recherche, publiés ou non, émanant des établissements d'enseignement et de recherche français ou étrangers, des laboratoires publics ou privés.

\section{(ㅇ)(1) $\$$}

Distributed under a Creative Commons Attribution - NonCommercial| 4.0 International 


\title{
Site-Selective Synthesis of Janus-type Metal-Organic Framework Composites**
}

\author{
Sudarat Yadnum, Jérome Roche, Eric Lebraud, Philippe Négrier, Patrick Garrigue, \\ Darren Bradshaw, * Chompunuch Warakulwit, Jumras Limtrakul, and Alexander Kuhn*
}

\begin{abstract}
Herein, bipolar electrochemistry is applied in a straightforward way to the site selective in situ synthesis of metal organic framework (MOF) structures, which have attracted tremendous interest in recent years because of their significant application potential, ranging from sensing to gas storage and catalysis. The novelty of the presented work is that the deposit can be intentionally confined to a defined area of a substrate without using masks or templates. The intrinsic site selectivity of bipolar electrochemistry makes it a method of choice to generate, in a highly controlled way, hybrid particles that may have different functionalities combined on the same particle. The wireless nature of electrodeposition allows the potential for mass production of such Janus type objects.
\end{abstract}

$M$ icroporous metal organic frameworks (MOFs) assem bled by coordination bonds between metal ions and organic ligands ${ }^{[1]}$ are of enormous importance for their applications in catalysis, gas separation, storage, drug delivery, and sensing. ${ }^{[2]}$ For MOFs to reach their full potential in these and other applications, it is necessary to process or directly prepare them in suitable application specific configurations, ${ }^{[3]}$ such as

[*] S. Yadnum, Dr. J. Roche, P. Garrigue, Prof. A. Kuhn Univ. Bordeaux, CNRS, ISM, UMR 5255, ENSCBP

33607 Pessac (France)

Email: kuhn@enscbp.fr

Homepage: http://www.enscbp.fr/nsysa/home asp

S. Yadnum, Dr. C. Warakulwit, Prof. J. Limtrakul

Department of Chemistry, Faculty of Science, Kasetsart University Bangkok 10900 (Thailand)

Prof. J. Limtrakul

PTT Group Frontier Research Center, PTT Public Company Limited 555 Vibhavadi Rangsit Road, Chatuchak, Bangkok 10900 (Thailand)

Dr. D. Bradshaw

School of Chemistry, University of Southampton

Highfield, Southampton, SO17 1BJ (UK)

E mail: D.Bradshaw@soton.ac.uk

E. Lebraud

CNRS, Univ. Bordeaux, ICMCB, UPR 9048

33600 Pessac (France)

P. Négrier

Laboratoire Ondes et Matière d'Aquitaine, CNRS UMR 5798 33405 Talence (France)

[**; The Thailand Research Fund (TRF) is acknowledged for a Royal Golden Jubilee Ph.D. Fellowship (3.C.KU/51/A.1) and the French Government for its contribution to this Ph.D. co tutelle program. D.B. thanks the European Research Council (ERC) for financial support (BIOMOF 258613). A.K. acknowledges support from the Institut Universitaire de France ANR project EMMA 00701. thin films and supported membranes, ${ }^{[4]}$ capsules, ${ }^{[5]}$ and composites. ${ }^{[6]}$ Often this involves MOF deposition, which is typically a bottom up process, occurring preferentially at an appropriately functionalized surface ${ }^{[7]}$ obtained with a chem ical or physical mask. ${ }^{[8]}$ Using these methods in combination with liquid based epitaxy, ${ }^{[9]}$ reactive seeding, ${ }^{[10]}$ or electro chemistry ${ }^{[11]}$ high quality oriented MOF thin films and crystal arrays with micron sized features have been prepared. ${ }^{[8,12]}$ Although significant progress has been made, challenges remain in the development of fast, inexpensive, and scalable fabrication processes, not only to facilitate MOF integration in real functional devices, ${ }^{[13]}$ but for the spatio selective preparation of MOF based structures. In particular, there are currently no satisfactory methods for the site selective deposition of MOFs onto 3 dimensional substrates, thus forming Janus type architectures; this is currently limited to MOF@MOF type structures, where a close lattice match between the two frameworks is required for efficient epitaxial growth of one MOF crystal onto or around another. ${ }^{[14]}$ There are, however, significant benefits to developing such a strategy for MOF composites when one considers the strong con currence between the inherent porosity and tuneable physical properties of MOFs with the applications of Janus structures in catalysis, drug delivery, optoelectronics, and biomedical imaging. ${ }^{[15]}$ Herein, we report for the first time the successful application of indirect bipolar electrodeposition (IBED) ${ }^{[16]}$ for the wireless and selective deposition of prototypical MOFs onto metallic wires and particles to prepare Janus type composite materials in a facile manner under mild conditions.

Bipolar electrochemistry (BE) with micrometer sized objects was first described by Fleischmann et al. ${ }^{[17]}$ When a conducting object is exposed to an electric field established between two electrodes in a solution, a positive and negative polarization occurs between the two opposite sides of the object where redox reactions can occur, if the polarization is strong enough. ${ }^{[18]}$ This concept has been explored in the context of various fields, including analytical chemistry, ${ }^{[19]}$ chemical motion, ${ }^{[20]}$ electronics, ${ }^{[21]}$ and materials science. ${ }^{[22]}$ Whereas BE is usually limited to deposits obtained from electroactive precursors, ${ }^{[23]}$ we have recently reported that insulating materials, including metal oxides and electropho retic paints, can be generated from non electroactive pre cursors. ${ }^{[16]}$ This IBED technique exploits an electrochemically triggered local $\mathrm{pH}$ change around the conducting objects, leading to controlled polymerization or precipitation of an insulating deposit, thus significantly extending the diversity of materials that can be prepared. The IBED approach is used in the present work to wirelessly generate reactive metal ions locally on the surface of metallic substrates that can 
subsequently react with ligand species in solution to form extended coordination based network structures. Although MOFs have previously been electrochemically prepared by anodic dissolution ${ }^{[24]}$ and cathodic electroreduction of base equivalents for ligand deprotonation, ${ }^{[25]}$ IBED is qualitatively distinct, as it permits wireless selective deposition of MOFs at one end or hemisphere of a substrate where polarization simultaneously generates the metal ions required for frame work growth and acts as a simple virtual mask without the need to chemically or physically block areas where deposition is not desired.

To demonstrate the application of IBED to MOFs, we initially selected the chemically and thermally stable tetrahe drally coordinated $\mathrm{Zn}$ imidazolate network [ $\left.\mathrm{Zn}(2 \mathrm{MeIm})_{2}\right]$ ZIF 8 (2 MeIm = 2 methylimidazole $),{ }^{[26]}$ due to its reliable synthesis in a range of solvents under mild conditions. ${ }^{[27]} \mathrm{We}$ employed a metallic $\mathrm{Zn}$ wire as both a metal source and substrate for selective deposition. To carry out these reac tions, one has to consider that in $\mathrm{BE}$ the polarization voltage generated between the two sides of an object with respect to the surrounding solution is proportional to the external electric field $(E)$ and the length of the object $(l)$ :

\section{$\Delta V \quad E \times l$}

In a first order approximation, $\Delta V$ must be at least equal to the difference between the formal potentials of the two involved redox couples. In the present case, oxidation of $\mathrm{Zn}$ metal occurs at the positively polarized side of a zinc wire (Figure 1a), based on the following redox couple:

a)

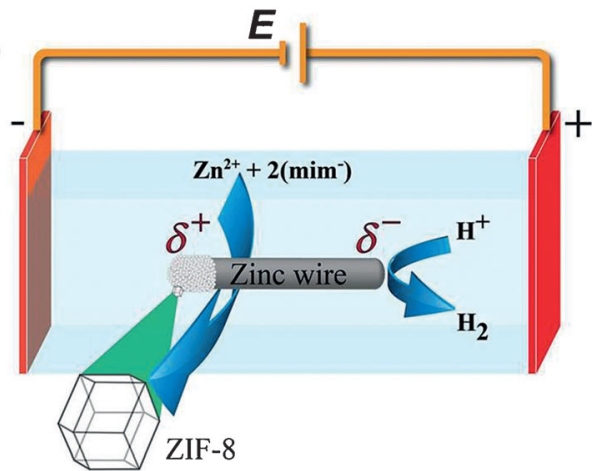

b)

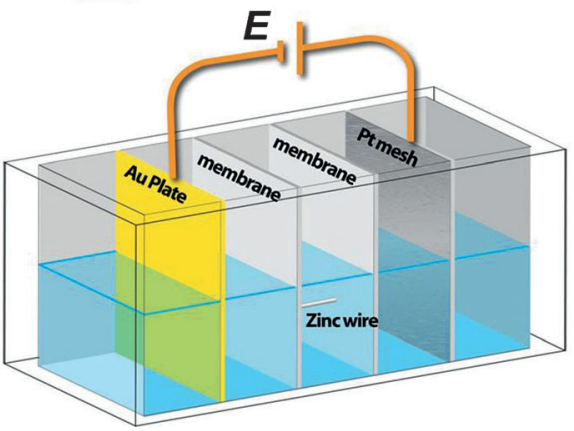

Figure 1. a) Mechanism of the formation of ZIF 8. Crystal growth on the anodically polarized side of a zinc wire is triggered by indirect bipolar electrodeposition (IBED). b) Design of the bipolar electrochem ical cell used for the synthesis of ZIF 8.
$\mathrm{Zn}^{2+}(\mathrm{aq})+2 \mathrm{e} \leftrightarrow \mathrm{Zn}(\mathrm{s}) ; E^{0} \quad 0.76 \mathrm{~V}$ vs. NHE

At the opposite side of the wire, protons are simultaneously reduced:

$2 \mathrm{H}^{+}(\mathrm{aq})+2 \mathrm{e} \quad \leftrightarrow \mathrm{H}_{2}(\mathrm{~g}) ; E^{0} \quad 0 \mathrm{~V}$ vs. $\mathrm{NHE}$

such that, under standard conditions, the combination of these two redox couples leads, from a thermodynamic point of view, to a spontaneous reaction between both redox couples. However, variable overpotentials from potential drops at the electrodes and in the solution, as well as slow kinetics, also need to be considered, and especially changes in $\mathrm{pH}$ will equally impact the potential difference. To experimentally estimate the potential difference required to drive the two redox reactions simultaneously at both ends of the wire with sufficiently high kinetics, cyclic voltammetry has been used (Figure S11).

The electrochemical cell for ZIF 8 synthesis was com posed of two electrodes, and a $1 \mathrm{~cm} \mathrm{Zn}$ wire was placed at the center between two Nafion membranes that are present to avoid parasitic reactions of the ligand at the feeder electrodes (Figure $1 \mathrm{~b}$ ). The two electrodes are separated by $3.5 \mathrm{~cm}$, and when applying a potential difference of $5 \mathrm{~V}$ between them, one can calculate (based on [Eq. 1]), that a potential drop of $1.4 \mathrm{~V}$ should occur between the two ends of the $\mathrm{Zn}$ wire; according to the CV shown in Figure S11 in the Supporting Information, this is sufficient to overcome possible over potentials and induce the required redox reactions at the opposite ends of the wire.

The $\mathrm{Zn}^{2+}$ ions produced at the positively polarized side of the wire undergo a chemical reaction with the $2 \mathrm{MeIm}$ linker group (Scheme 1). In a control experiment where a $\mathrm{Zn}$ wire

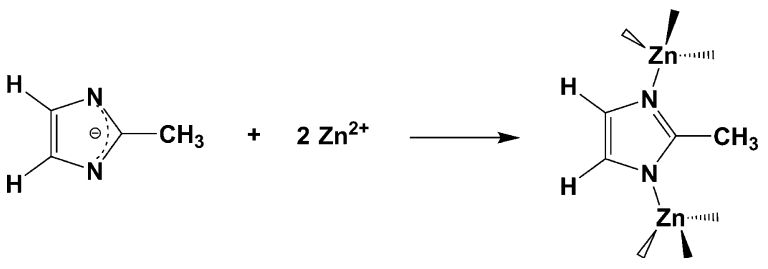

Scheme 1. Reaction of the 2 methylimidazole linker with $\mathrm{Zn}^{2+}$ ions at the surface of a bipolar electrode to form the basic building unit of ZIF 8 crystals.

was left in an aqueous solution of the ligand for three days without applying a potential (Figure $2 \mathrm{a}$ ), almost no sponta neous reaction occurs, with only a few small deposits located at random positions along the wire. However, when applying the electric field, ZIF 8 is generated as a crystalline deposit exclusively at the positively polarized end of the wire (Figure 2b).

The SEM images of the IBED synthesized ZIF 8 samples using different potentials, electrodeposition times, and con centrations of $2 \mathrm{MeIm}$ are shown in Figure 2. In contrast to previous reports where no ZIF 8 deposition occurred onto "wired" $\mathrm{Zn}$ anodes, ${ }^{[24 \mathrm{~b}]}$ we clearly observe the formation of surface bound ZIF 8 crystals. As a consequence of the 


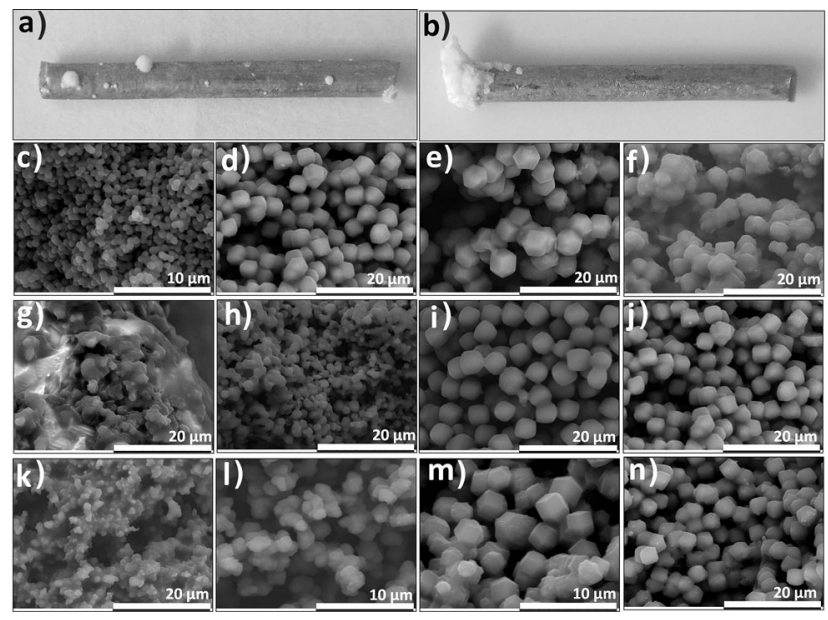

Figure 2. Site selective modification of a zinc wire with ZIF 8: a) Con trol experiment without electric field after three days in a solution containing $2 \mathrm{Melm}(1.376 \mathrm{M})$ and $\mathrm{Na}_{2} \mathrm{SO}_{4}(0.05 \mathrm{M})$. b) Synthesized by the IBED method $\left(6 \mathrm{~V}, 60 \mathrm{~min}, 1.376 \mathrm{M} 2 \mathrm{Melm}, 0.05 \mathrm{M} \mathrm{Na}_{2} \mathrm{SO}_{4}\right)$. $\mathrm{c}$ n) SEM images of ZIF 8, as synthesized by IBED. c f) Crystals obtained for different external potential differences with $2 \mathrm{Melm}$ $(1.376 \mathrm{M})$ after $60 \mathrm{~min}$ reaction time: c) $5 \mathrm{~V}$, d) $6 \mathrm{~V}$, e) $7 \mathrm{~V}$, and f) $8 \mathrm{~V}$. $\mathrm{g}$ j) Deposits observed for different electrodeposition times with 2 Melm $(1.376 \mathrm{M})$ and $6 \mathrm{~V}$ between the external feeder electrodes: g) $2 \mathrm{~min}$, h) $10 \mathrm{~min}$, i) $30 \mathrm{~min}$, and j) $60 \mathrm{~min}$. k n) Morphology of the obtained crystals for different concentrations of $2 \mathrm{Melm}$ after $60 \mathrm{~min}$ electrodeposition time at $6 \mathrm{~V}: \mathrm{k}) 0.344 \mathrm{M}$, I) $0.688 \mathrm{M}, \mathrm{m}) 1.032 \mathrm{M}$, and n) $1.376 \mathrm{M}$.

polarization of the substrate, deposition continues at one end of the wire with increasing reaction time (Figure $2 \mathrm{~b}$ ), rather than leading to even coverage, as observed with conventional electrochemical systems. ${ }^{[24 \mathrm{~b}]}$ This strongly suggests that the electrochemically generated $\mathrm{Zn}^{2+}$ ions can migrate through the porous ZIF 8 deposit and/or interstices between crystals to continue to induce growth at its outer surface. Eventually, linker could also diffuse through the deposit towards the inner interface between zinc and the MOF, ${ }^{[28]}$ but in a less efficient way than the positively charged zinc ions attracted by the feeder cathode.

For the optimized synthesis parameters of $6 \mathrm{~V}$ of external potential applied for $60 \mathrm{~min}$ (Figure $2 \mathrm{~d}, \mathrm{j}, \mathrm{n}$ ), the obtained ZIF 8 is composed of crystals with a rhombic dodecahedral morphology and uniform size (ca. $4 \mu \mathrm{m}$ ), which matches well with the reported morphology for this zeotype extended network. ${ }^{[27 b]}$ For IBED MOF generation, the external electric field applied during synthesis plays an important role with respect to the crystal size and morphology of the generated ZIF 8, under otherwise identical conditions. As shown in Figure $2 \mathrm{c}$ e, the crystal size increases when increasing the potential difference, at constant $2 \mathrm{MeIm}$ concentration. In all cases, rhombic dodecahedral crystals are formed, and the observed size increase is consistent with a decrease in the 2 $\mathrm{MeIm} / \mathrm{Zn}^{2+}$ ratio, as reported for bulk $\mathrm{ZIF} 8$ synthesis in water. ${ }^{[29]}$ However, crystal morphology becomes less well defined at too high potentials. At $8 \mathrm{~V}$ (Figure $2 \mathrm{f}$ ) for example, the particles appear fused together, possibly as a result of co deposition of impurity phases, arising from the low $2 \mathrm{MeIm} /$ $\mathrm{Zn}^{2+}$ ratio, ${ }^{[29]}$ owing to the relatively rapid release of $\mathrm{Zn}^{2+}$ at this potential. For such a relative deficiency of ligand, the formed zinc ions are more likely to form zinc hydroxides (Figures S1, S2, and S4). This strongly suggests that a close match between the release rate of metal ions (which is readily controlled by the applied potential), MOF nucleation, and growth kinetics is required to form well defined crystals.

Electrodeposition time also affects the amount and morphology of the product (Figure $2 \mathrm{~g} \mathrm{j}$ ), and as expected, the amount of product and crystal size increases and morphology becomes better defined with increasing reaction time. Recent reports based on studies performed in situ on early stage ZIF 8 growth using $\mathrm{SAXS}^{[30]}$ and time resolved static light scattering ${ }^{[31]}$ indicate that nucleation is a slow continuous process, whereas crystal growth is more rapid. However the growth mechanism of coordination based materials under the synthesis conditions present around bipolar electrodes is complex, ${ }^{[32]}$ and local effects such as $\mathrm{pH}$ and concentration gradients certainly play an important role.

Figure $2 \mathrm{k} n$ show SEM images of ZIF 8 prepared with different concentrations of $2 \mathrm{MeIm}$, keeping the electro deposition time and the applied electric field constant at $60 \mathrm{~min}$ and $6 \mathrm{~V}$, respectively. Increasing the $2 \mathrm{MeIm} / \mathrm{Zn}^{2+}$ molar ratio also improves the crystal morphology and highly faceted crystals are obtained at the highest concentrations of 2 MeIm. Under these conditions, all the $\mathrm{Zn}^{2+}$ ions produced react with the organic linker, and the excess 2 MeIm could potentially act to stabilize and/or control ZIF 8 crystal growth. ${ }^{[31]}$ At lower 2 MeIm concentrations however, the $\mathrm{Zn}$ wire is still oxidized at the same rate, but insufficient linker is available to lock all of the metal ions into the extended ZIF structure, thus leading to the formation of other $\mathrm{Zn}$ contain ing species, including oxides and/or hydroxides, as previously observed for the aqueous synthesis of bulk ZIF 8 at low 2 $\mathrm{MeIm} / \mathrm{Zn}$ ratios. ${ }^{[29]}$ This is an analogous situation to using high potentials, as shown in Figure $2 \mathrm{f}$ (see also Figures S1, S2, and S4).

The ZIF 8 crystals obtained by IBED were characterized by powder X ray diffraction (PXRD) (Figure 3) and infrared (IR) spectroscopy (see the Supporting Information). Figure 3 shows diffraction peak positions and relative diffraction intensities of ZIF 8 products recorded from three samples obtained from solutions containing different concentrations of $2 \mathrm{MeIm}$ after applying a potential of $6 \mathrm{~V}$ for $60 \mathrm{~min}$. The products prepared at high concentrations of $2 \mathrm{MeIm}$ were assigned to sodalite (SOD) network type structures and a typical reflection pattern for the synthesized ZIF 8 corre sponding to the (011), (002), (112), (022), (013), and (222) planes was observed, which is in excellent agreement with those described in the literature. ${ }^{[33]}$

Control experiments that were carried out with a zinc wire attached and electrically connected to the working electrode in a normal three electrode setup only resulted in homoge neous coverage of the wire with the MOF, but never in a site selective deposition (see the Supporting Information). This clearly demonstrates that the proposed approach is unique in terms of the formation of these Janus type objects.

To illustrate the general validity of the IBED concept for site selective MOF deposition, we also investigated the 


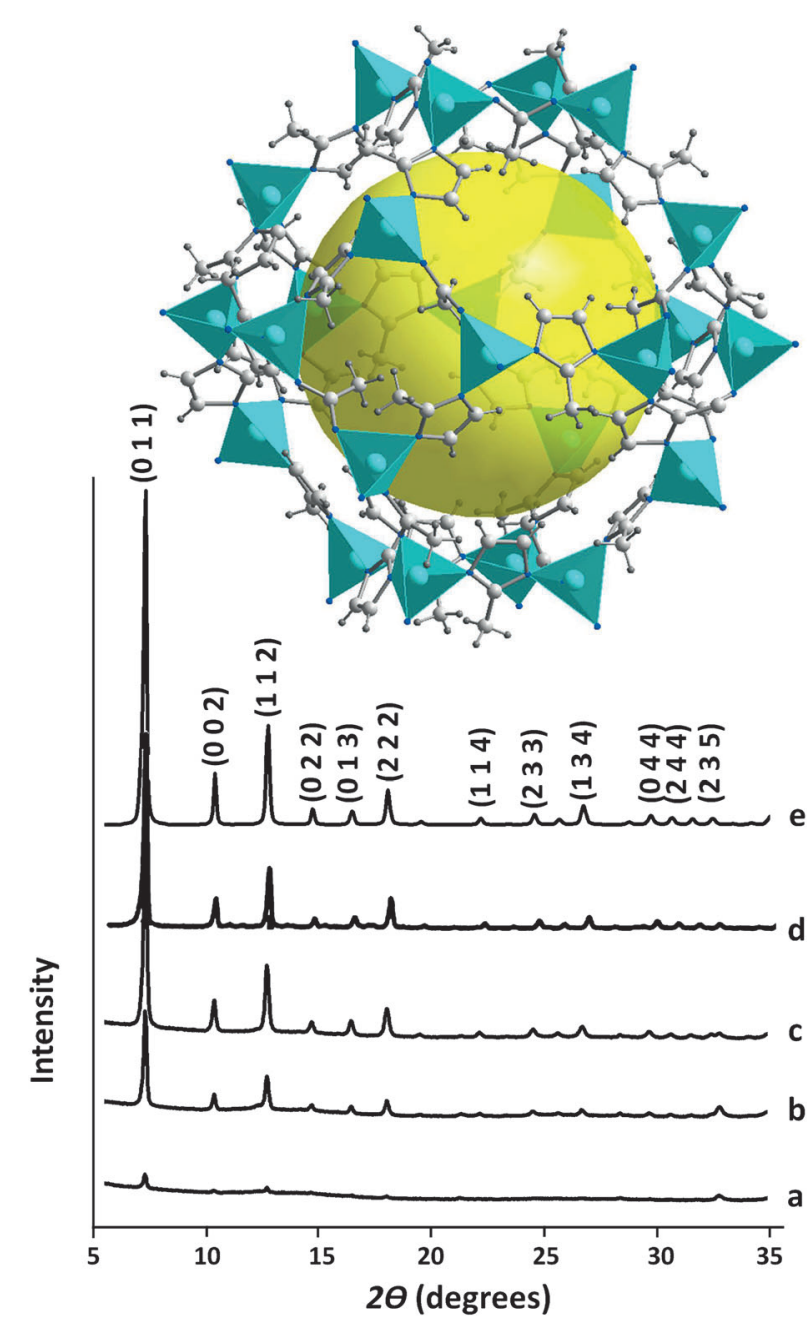

Figure 3. Structure of the ZIF 8 sodalite cage refined from the powder data of IBED deposited material (top). PXRD patterns illustrating the structural evolution of ZIF 8 obtained by IBED when applying an electric field of 6 Volts for $60 \mathrm{~min}$ as a function of the concentration of 2 methylimidazole: a) $0.688 \mathrm{M}$, b) $1.032 \mathrm{M}$, c) $1.376 \mathrm{M}$, d) XRD pattern of ZIF 8 from literature, ${ }^{[33]}$ and e) Simulated XRD pattern of ZIF 8 powder.

formation of HKUST $1,{ }^{[34]}$ a commercially important micro porous framework $\left[\mathrm{Cu}_{3}(\mathrm{BTC})_{2}\left(\mathrm{H}_{2} \mathrm{O}\right)_{3}\right](\mathrm{BTC}=1,3,5$ benzen tricarboxylate). HKUST 1 has previously been prepared electrochemically through anodic dissolution of wired $\mathrm{Cu}$ electrodes $^{[24]}$ and selectively deposited onto printed circuit boards. ${ }^{[11]}$ In the current work, an isotropic $\mathrm{Cu}$ metal bead was employed as the substrate where the wireless oxidation of copper in ethanol (Figure 4b) produces the $\mathrm{Cu}^{2+}$ ions necessary for the local formation of the MOF on one hemisphere only, leading to a well defined Janus type com posite particle. The position and extension of the blue crystalline MOF deposit can be readily controlled by the applied external voltage owing to the change of polarization (Figure $4 \mathrm{c}, \mathrm{d}$ ). When the material deposited on the anodic side of this Janus object is characterized by SEM, the familiar octahedral block like crystals of HKUST 1 are observed, further confirming the successful generation of the MOF (see the Supporting Information) under these conditions. As the

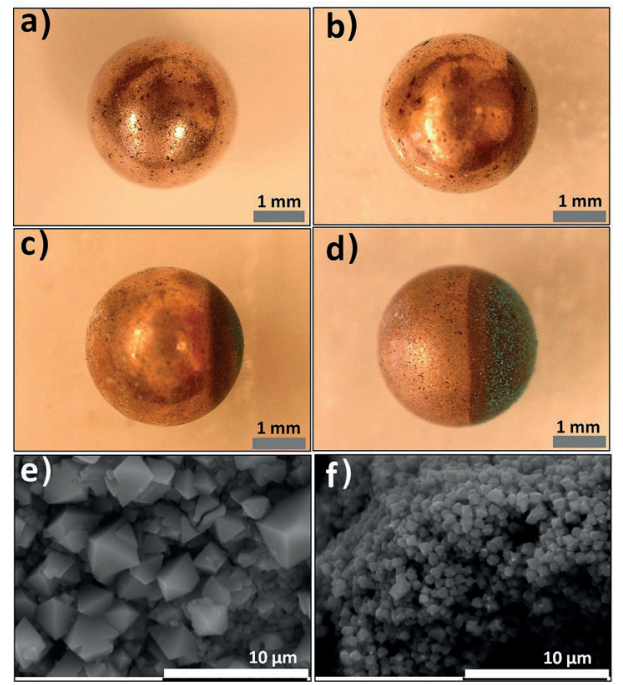

Figure 4. Site selective modification of a copper bead ( $3 \mathrm{~mm}$ diameter) with HKUST 1: a) bead before modification, b) after applying an external potential difference of 10 Volts for $60 \mathrm{~min}$ without 1,3,5 benzenetricarboxylic acid, and c,d) bead obtained at $10 \mathrm{~V}$ and $20 \mathrm{~V}$, respectively, in the presence of 1,3,5 benzenetricarboxylic acid $(0.08 \mathrm{M})$ in ethanol after 60 min reaction time. e,f) SEM images of HKUST 1 as synthesized by IBED on one side of the copper bead; crystals obtained at $10 \mathrm{~V}$ and $20 \mathrm{~V}$, respectively, in 1,3,5 benzenetricarboxylic acid $(0.08 \mathrm{M})$ after $60 \mathrm{~min}$ reaction time.

applied potential increases from $10 \mathrm{~V}$ to $20 \mathrm{~V}$, the crystal size decreases in agreement with previous studies on the electro chemical deposition of HKUST $1 .{ }^{[11]}$ The deposit has been further characterized using XRD and FTIR spectroscopy (Figures S3 and S10). Control experiments exposing the copper bead to the ligand solution without applying an electric field did not result in the formation of HKUST 1, even after three days (see the Supporting Information). Furthermore, attaching the bead to the working electrode of a three electrode setup leads to a homogeneous and complete MOF coverage (see the Supporting Information), which indicates that the bipolar setup is absolutely crucial to produce the asymmetric composite particles.

In summary, we report here for the first time the straightforward and site selective synthesis of MOF com pounds by indirect bipolar electrochemistry with two repre sentative proof of principle experiments for the asymmetric generation of MOFs on the surface of isotropic and aniso tropic substrates. The characterization of the obtained com pounds confirms their successful synthesis, where crystal size and morphology can be tuned in a facile manner through modulation of linker concentration, electrodeposition time, and the magnitude of the external electric field. This concept might be generalized for the synthesis of many other MOF compounds, thus allowing inexpensive and green access to this important family of microporous materials, and leading to a new generation of MOF based Janus type composites with applications in catalysis, separation, storage, and sensing. 
Keywords: composites - electrochemistry . electrocrystallization · Janus particles .

metal organic frameworks

[1] a) S. Kitagawa, R. Kitaura, S. I. Noro, Angew. Chem. 2004, 116, 2388 2430; Angew. Chem. Int. Ed. 2004, 43, 2334 2375; b) G. Férey, Chem. Soc. Rev. 2008, 37, 191 214; c) C. Janiak, J. K. Vieth, New J. Chem. 2010, 34, 23662388.

[2] J. R. Long, O. M. Yaghi, Chem. Soc. Rev. 2009, 38, 12131214.

[3] D. Bradshaw, A. Garai, J. Huo, Chem. Soc. Rev. 2012, 41, 2344 2381.

[4] O. Shekhah, J. Liu, R. A. Fischer, C. Woll, Chem. Soc. Rev. 2011, 40, 10811106.

[5] R. Ameloot, F. Vermoortele, W. Vanhove, M. B. J. Roeffaers, B. F. Sels, D. E. De Vos, Nat. Chem. 2011, 3, 382387.

[6] A. Ahmed, M. Forster, R. Clowes, D. Bradshaw, P. Myers, H Zhang, J. Mater. Chem. A 2013, 1, 32763286.

[7] D. Zacher, O. Shekhah, C. Woll, R. A. Fischer, Chem. Soc. Rev. 2009, 38, 14181429.

[8] P. Falcaro, D. Buso, A. J. Hill, C. M. Doherty, Adv. Mater. 2012 24, 31533168.

[9] O. Shekhah, H. Wang, S. Kowarik, F. Schreiber, M. Paulus, M. Tolan, C. Sternemann, F. Evers, D. Zacher, R. A. Fischer, C. Wöll, J. Am. Chem. Soc. 2007, 129, 1511815119.

[10] Y. Hu, X. Dong, J. Nan, W. Jin, X. Ren, N. Xu, Y. M. Lee, Chem. Commun. 2011, 47, 737739.

[11] R. Ameloot, L. Stappers, J. Fransaer, L. Alaerts, B. F. Sels, D. E. De Vos, Chem. Mater. 2009, 21, 25802582.

[12] A. Bétard, R. A. Fischer, Chem. Rev. 2012, 112, 10551083.

[13] M. D. Allendorf, A. Schwartzberg, V. Stavila, A. A. Talin, Chem. Eur. J. 2011, 17, 1137211388.

[14] S. Furukawa, K. Hirai, K. Nakagawa, Y. Takashima, R. Matsuda, T. Tsuruoka, M. Kondo, R. Haruki, D. Tanaka, H. Sakamoto, S Shimomura, O. Sakata, S. Kitagawa, Angew. Chem. 2009, 121, 1798 1802; Angew. Chem. Int. Ed. 2009, 48, 17661770.

[15] Janus Particle Synthesis Self Assembly and Applications (Eds.: S. Jiang, S. Granick), The Royal Society of Chemistry, London, 2012.

[16] G. Loget, J. Roche, E. Gianessi, L. Bouffier, A. Kuhn, J. Am. Chem. Soc. 2012, 134, 2003320036.

[17] M. Fleischmann, J. Ghoroghchian, D. Rolison, S. Pons, J. Phys. Chem. 1986, 90, 63926400.

[18] a) G. Loget, A. Kuhn, Anal. Bioanal. Chem. 2011, 400, 1691 1704; b) F. Mavré, R. K. Anand, D. R. Laws, K. F. Chow, B. Y. Chang, J. A. Crooks, R. M. Crooks, Anal. Chem. 2010, 82, 8766 8774.

[19] a) S. E. Fosdick, K. N. Knust, K. Scida, R. M. Crooks, Angew. Chem. Int. Ed. 2013, 52, 10438 10456; b) J. P. Guerrette, S. M.
Oja, B. Zhang, Anal. Chem. 2012, 84, 1609 1616; c) J. P. Guerrette, S. J. Percival, B. Zhang, J. Am. Chem. Soc. 2013, 135,855861

[20] a) G. Loget, A. Kuhn, J. Am. Chem. Soc. 2010, 132, 15918 15919; b) G. Loget, A. Kuhn, Lab Chip 2012, 12, 1967 1971; c) G. Loget, A. Kuhn, Nat. Commun. 2011, 2, 535.

[21] J. C. Bradley, H. M. Chen, J. Crawford, J. Eckert, K. Ernazarova, T. Kurzeja, M. Lin, M. McGee, W. Nadler, S. G. Stephens, Nature 1997, 389, 268271.

[22] a) C. Ulrich, O. Andersson, L. Nyholm, F. Björefors, Angew. Chem. 2008, 120, 3076 3078; Angew. Chem. Int. Ed. 2008, 47, 3034 3036; b) S. Ramakrishnan, C. Shannon, Langmuir 2010, 26, 4602 4606; c) Y. Ishiguro, S. Inagi, T. Fuchigami, Langmuir 2011, 27, 7158 7162; d) J. C. Bradley, S. Babu, A. Mittal, P. Ndungu, B. Carroll, B. Samuel, J. Electrochem. Soc. 2001, 148, C647 C651; e) J. C. Bradley, S. Babu, P. Ndungu, Fullerenes Nanotubes Carbon Nanostruct. 2005, 13, 227 237; f) S. Babu, P. Ndungu, J. C. Bradley, M. Rossi, Y. Gogotsi, Microfluid. Nano fluid. 2005, 1, 284 288; g) G. Loget, D. Zigah, L. Bouffier, N. Sojic, A. Kuhn, Acc. Chem. Res. 2013, 46, 25132523.

[23] G. Loget, V. Lapeyre, P. Garrigue, C. Warakulwit, J. Limtrakul, M. H. Delville, A. Kuhn, Chem. Mater. 2011, 23, 25952599.

[24] a) U. Mueller, M. Schubert, F. Teich, H. Puetter, K. Schierle Arndt, J. Pastre, J. Mater. Chem. 2006, 16, 626 636; b) A. M. Joaristi, J. Juan Alcaniz, P. Serra Crespo, F. Kapteijn, J. Gascon, Cryst. Growth Des. 2012, 12, 34893498.

[25] M. Li, M. Dincă, J. Am. Chem. Soc. 2011, 133, 1292612929.

[26] K. S. Park, Z. Ni, A. P. Côté, J. Y. Choi, R. Huang, F. J. Uribe Romo, H. K. Chae, M. O'Keeffe, O. M. Yaghi, Proc. Natl. Acad. Sci. USA 2006, 103, 1018610191.

[27] a) Y. Pan, Y. Liu, G. Zeng, L. Zhao, Z. Lai, Chem. Commun. 2011, 47, 2071 2073; b) J. Cravillon, S. Münzer, S. J. Lohmeier, A. Feldhoff, K. Huber, M. Wiebcke, Chem. Mater. 2009, 21, 14101412.

[28] M. Li, M. Dincă, Chem. Sci. 2014, 5, 107111.

[29] K. Kida, M. Okita, K. Fujita, S. Tanaka, Y. Miyake, CrystEng Comm 2013, 15, 17941801.

[30] J. Cravillon, C. A. Schrçder, R. Nayuk, J. Gummel, K. Huber, M. Wiebcke, Angew. Chem. 2011, 123, 8217 8221; Angew. Chem. Int. Ed. 2011, 50, 80678071.

[31] J. Cravillon, R. Nayuk, S. Springer, A. Feldhoff, K. Huber, M. Wiebcke, Chem. Mater. 2011, 23, 21302141.

[32] Z. Fattah, J. Roche, P. Garrigue, D. Zigah, L. Bouffier, A. Kuhn, ChemPhysChem 2013, 14, 20892093.

[33] S. R. Venna, J. B. Jasinski, M. A. Carreon, J. Am. Chem. Soc. 2010, 132, 1803018033.

[34] S. S. Y. Chui, S. M. F. Lo, J. P. H. Charmant, A. G. Orpen, I. D. Williams, Science 1999, 283, 11481150. 